\title{
Synthesis and characterization of polycaprolactone/acrylic acid (PCL/AA) hydrogel for controlled drug delivery
}

\author{
NAZAR MOHAMMAD RANJHA*, JAHANZEB MUDASSIR and SAJID MAJEED \\ Department of Pharmacy, Bahauddin Zakariya University, Multan 60800, Pakistan
}

MS received 19 March 2010; revised 8 February 2011

\begin{abstract}
In the present work biodegradable pH-sensitive polycaprolactone/acrylic acid (PCL/AA) hydrogels have been developed using ethylene glycol dimethacrylate (EGDMA) as a cross-linker and benzoyl peroxide as initiator. For these prepared hydrogels swelling studies, sol-gel fraction analysis and porosity measurements were performed. Results show that swelling of the hydrogels decreases on increasing the concentration of PCL and EGDMA, however swelling of hydrogels increases on increasing the concentration of AA. Results of sol-gel fraction analysis show that gel fraction increases on increasing concentration of monomer AA, polymer PCL as well as cross-linker EGDMA. As far as porosity is concerned, it increases on increasing the concentration of $\mathrm{AA}$ and PCL while porosity decreases on increasing the concentration of EGDMA. Hydrogels were characterized by measuring diffusion coefficient $(D)$ and equilibrium water content (EWC). Network formation, morphology and crystallinity of PCL/AA hydrogels were investigated using FTIR, SEM and XRD, respectively. Tramadol hydrochloride was loaded as model drug and its release pattern was analysed using various kinetic models like zero order, first order, Higuchi and Peppas. Results indicated that most of the samples followed non-Fickian release mechanism.
\end{abstract}

Keywords. Polycaprolactone; acrylic acid; ethylene glycol dimethacrylate; hydrogels; tramadol.

\section{Introduction}

Copolymers contain various physiochemical properties which are used in medicine and drug delivery applications. These modified materials are extensively used to achieve targeted drug delivery. Hydrogel application areas include (i) stimuli responsive system, (ii) ocular applications, (iii) dental applications, (iv) injectable polymers, (v) sustained release drug delivery system, (vi) implants, (vii) transdermal delivery systems and (viii) epidermal applications (Peppas et al 2000). Hydrogel have affinity to absorb water (up to $90 \% \mathrm{wt}$ ) due to its hydrophilic properties (Peppas and Mikos 1986). Water absorbing ability of hydrogel depends on $\mathrm{pH}$ of the biological fluid and polymer composition (Peppas and Khare 1993). Recently, numerous pH-sensitive hydrogels have been reported (Mudassir and Ranjha 2008; Ranjha and Mudassir 2008). Unfortunately these pH-sensitive hydrogels were not biodegradable and there was great need for $\mathrm{pH}$-sensitive and biodegradable polymers. Therefore, the objective of present study was to synthesize $\mathrm{pH}$ sensitive, biodegradable materials which could fulfill both of these requirements. In order to synthesize such materials numerous synthetic monomers/polymers are used. Among them biodegradable aliphatic polyesters such as

\footnotetext{
*Author for correspondence (drnazarmranjha@yahoo.com)
}

poly( $\varepsilon$-caprolactone) (PCL), poly(lactic acid) (PLA), poly(glycolic acid) (PGA) and their copolymers are most important (Chiellini and Solaro 1996; Jeong et al 1997; Masahiko 2002). PCL has gained much attention as ideal material for drug delivery and other applications (Mondrinos et al 2006). It is a semi-crystalline, hydrophobic polymer with relatively polar ester group and five nonpolar methylene groups in its repeating unit (Seregin and Coffer 2006). PCL is mostly synthesized by ring opening polymerization method from $\varepsilon$-caprolactone monomers (Kim et al 2004). However, PCL due to its crystalline and hydrophobic nature, degrade rather slowly and is less biocompatible with soft tissue, which limits its use for clinical applications. Therefore, in the present study, modification in PCL is proposed. PCL forms interpolymer complexes by H-bonding with carboxylic groups of acrylic acid (Hong et al 2005; Santiago et al 2006). Acrylic acid has properties to develop various intermolecular interactions to synthesize hydrogels with other polymers. Swelling behaviour of hydrogel are strongly influenced by intermolecular interaction of acrylic acid such as H-bonding and electrostatic interaction (Bromberg et al 2004; Devine and Higginbotham 2005). Wu (2005) synthesized and studied the effect of replacing PCL with AA grafted PCL(PCL-g-AA) on the structure and properties of $\mathrm{PCL} /$ chitosan composite. In another study by Wang et al (2009), biodegradable pH-sensitive hydrogel based on poly( $\varepsilon$-caprolactone) (PCL), methoxy- 
poly(ethylene glycol) (MPEG) and methacrylic acid (MAA) were prepared by UV-initiated free radical polymerization. EGDMA was used as crosslinking agent and strengthening of intermolecular bonding was reported on increasing the concentration of crosslinking agent. It was suggested that swelling and drug release from hydrogel was influenced by concentration of EGDMA (Arica et al 2009).

In this study, novel biodegradable and $\mathrm{pH}$-sensitive PCL/AA hydrogels were successfully prepared by combining PCL and AA in the presence of EGDMA as crosslinker and benzoyl peroxide as initiator. Selected samples were loaded with tramadol $\mathrm{HCl}$ as model drug. Effect of varying concentration of PCL, AA and EGDMA was studied on swelling and on drug release behaviour in various USP phosphate buffer solutions having different pH. Drug release was analysed using various kinetic models like zero order, first order (Higuchi 1963; Peppas 1985). Diffusion coefficients $(D)$ and equilibrium water content (EWC) were also calculated. Role of PCL, AA and EGDMA was investigated on sol-gel fraction and porosity. Structure, morphology and crystallinity of PCL/ AA hydrogel were studied using FTIR, SEM and XRD, respectively.

\section{Materials and methods}

\subsection{Materials}

The monomer, polymer and cross-linker used were acrylic acid (AA) (Merck, Germany), polycaprolactone (PCL), (MW, 14000) (Aldrich, Germany) and ethylene glycol dimethacrylate (EGDMA) (Aldrich, Germany), respectively. Ethanol was obtained from (Merck, Germany). Dichloromethane (DCM) was used as co-solvent and purchased from (BDH, England). Benzoyl peroxide (Merck, Germany) was used as initiator. Potassium bromide $(\mathrm{KBr})$ of FTIR grade was purchased from Fisher Scientific, UK. Potassium dihydrogen phosphate, sodium chloride, sodium hydroxide and hydrochloric acid (Merck, Germany) used were of analytical grade.

\subsection{Synthesis of PCL/AA hydrogels}

Series of crosslinked hydrogels having different compositions of PCL and AA were synthesized as given in table 1. Procedure for synthesis of hydrogels was used after modification in previously described method ( $\mathrm{Li}$ et al 2006; Mudassir and Ranjha 2008; Ranjha and Mudassir 2008). Weighed amount of PCL was added into dichloromethane (DCM) and stirred until clear solution was obtained. Then ethanol was added with constant stirring. Benzoyl peroxide was separately dissolved in AA. Two solutions were mixed and varying amounts of EGDMA was added in the solution mixture. DCM was evaporated with constant stirring for $2 \mathrm{~h}$. Final weight of the solution was made up to $100 \mathrm{~g}$ with ethanol and it was mixed for $30 \mathrm{~min}$. After mixing thoroughly, final solution was poured into glass tubes (pyrex). Air above the solution in the tube or any dissolved oxygen was removed by bubbling the nitrogen for 15-20 min which act as free radical scavenger. For polymerization, solution was heated in water bath at $45^{\circ} \mathrm{C}$ for $1 \mathrm{~h}, 50^{\circ} \mathrm{C}$ for $2 \mathrm{~h}, 55^{\circ} \mathrm{C}$ for $3 \mathrm{~h}$, $60^{\circ} \mathrm{C}$ for $4 \mathrm{~h}$ and $65^{\circ} \mathrm{C}$ for $12 \mathrm{~h}$. Hydrogels obtained were cut into discs of $6 \mathrm{~mm}$ in size and immersed into $50: 50 \mathrm{v} / \mathrm{v}$ solutions of ethanol and water. These gel discs were thoroughly washed until the $\mathrm{pH}$ of ethanol water mixture was same as the mixture before washing. Hydrogels obtained were dried under vacuum at $45^{\circ} \mathrm{C}$ to constant weight and stored in desiccators for further use. Structures of monomers and cross-linkers used in the preparation of hydrogels are given in table 2 .

\subsection{Swelling behaviour of PCL/AA hydrogels}

Swelling studies were performed in $0.05 \mathrm{M}$ USP phosphate buffer solution of $\mathrm{pH} 1 \cdot 2,5 \cdot 5,6.5$ and 7.5 to simulate $\mathrm{pH}$ of the gastric and small intestine, respectively. Swelling studies of washed and dried hydrogels were performed by allowing them to swell in the solution of varying $\mathrm{pH}$ at room temperature. Swollen gels were removed from solution after regular intervals of time, blotted using filter paper, weighed and were placed in the same solution. Dynamic swelling ratios of hydrogels were calculated using the following equation

$$
q=W_{\mathrm{h}} / W_{\mathrm{d}},
$$

where $W_{\mathrm{h}}$ is the weight of swollen gel at time $t$, and $W_{\mathrm{d}}$ the initial weight of dry gel. The procedure was continued till constant weight was obtained. Equilibrium water content (EWC) was calculated as under

$$
\mathrm{EWC}=\frac{m_{\mathrm{eq}}-m_{0}}{m_{\mathrm{eq}}} \times 100 .
$$

\subsection{Preparation of tramadol HCl loaded PCL/AA hydrogels}

Drug loading and release studies were performed in those samples which showed maximum swelling. Weighed dried discs were placed in drug solution. A $1 \% \mathrm{w} / \mathrm{v}$ drug solution was prepared. Solvent used for drug loading was a mixture of $50 \% \mathrm{v} / \mathrm{v}$ ethanol water mixture. After attaining the equilibrium swelling in drug solution, hydrogels were first dried at room temperature and then in an oven at $45^{\circ} \mathrm{C}$ until constant weight was obtained.

\subsection{Determination of tramadol $\mathrm{HCl}$ loading in gels}

Amount of drug loaded in hydrogels was calculated using the following three methods (Serraa et al 2006; Siemoneit 
Table 1. Optimum reaction parameters for synthesis of PCL/AA hydrogels.

\begin{tabular}{lccc}
\hline $\begin{array}{l}\text { Sample } \\
\text { code }\end{array}$ & $\begin{array}{c}\text { PCL solution } \\
\text { concentration }(\% \mathrm{w} / \mathrm{w})\end{array}$ & $\begin{array}{c}\text { AA solution } \\
\text { concentration }(\% \mathrm{w} / \mathrm{w})\end{array}$ & EGDMA : AA \\
\hline$S_{1}$ & 4 & 44 & $1: 100$ \\
$S_{2}$ & 4 & 52 & $1: 100$ \\
$S_{3}$ & 4 & 60 & $1: 100$ \\
$S_{4}$ & 4 & 48 & $1: 100$ \\
$S_{5}$ & 8 & 48 & $1: 100$ \\
$S_{6}$ & 12 & 48 & $1: 100$ \\
$S_{7}$ & 4 & 52 & $0 \cdot 25: 100$ \\
$S_{8}$ & 4 & 52 & $0 \cdot 75: 100$ \\
$S_{9}$ & 4 & 52 & $1 \cdot 25: 100$ \\
\hline
\end{tabular}

Table 2. Used monomers and cross-linkers in preparation of hydrogels.

\begin{tabular}{lll}
\hline & \multicolumn{1}{c}{ Formula } & Abbreviations \\
\hline Acrylic acid & $\mathrm{CH}_{2} \mathrm{CHOOH}$ & AA \\
Polycaprolactone & {$\left[\mathrm{O}\left(\mathrm{CH}_{2}\right)_{5} \mathrm{C}=\mathrm{O}\right]_{n}$} & PCL \\
Benzoyl peroxide & {$\left[\mathrm{C}_{6} \mathrm{H}_{5} \mathrm{C}(\mathrm{O})\right]_{2} \mathrm{O}_{2}$} & BPO \\
Ethylene glycol dimethacrylate & {$\left[\mathrm{H}_{2} \mathrm{C}=\mathrm{CCH}_{3} \mathrm{COOCH}_{2}\right]_{2}$} & EGDMA \\
\hline
\end{tabular}

et al 2006). In the first method following equation was used to calculate the amount of drug loaded in hydrogels

$$
\begin{aligned}
& \text { Amount of drug }=W_{\mathrm{D}}-W_{\mathrm{d}}, \\
& \text { Drug loading }(\%)=\left[\frac{W_{\mathrm{D}}-W_{\mathrm{d}}}{W_{\mathrm{d}}}\right] \times 100,
\end{aligned}
$$

where $W_{\mathrm{D}}$ and $W_{\mathrm{d}}$ are the weights of dried hydrogels after and before immersion in drug solution. In the second method, amount of drug entrapped in hydrogels was calculated by repeatedly extracting the weighed quantity of drug loaded gels in $50 \%(\mathrm{v} / \mathrm{v})$ ethanol water mixture. Each time $25 \mathrm{ml}$ fresh $50 \%$ (v/v) ethanol water mixture was used until there was no drug present in the mixture. Drug concentration was determined spectrophotometrically. Sum of the drug present in all portions was considered as total amount of drug entrapped in the gels. While in the third method, weighed gel discs were placed in the drug solution until they attained equilibrium swelling. Loaded gels were weighed again after blotting using blotting paper. Difference in weight before and after swelling was the weight of drug solution. Volume of drug solution absorbed by gel disc was calculated by knowing the density and weight of drug solution. After calculating the volume of drug solution, amount of drug absorbed by gel discs were also calculated.

\subsection{Drug release studies}

Drug release studies were performed up to $12 \mathrm{~h}$ period. For this purpose, weighed hydrogels disks were immersed in $500 \mathrm{ml}$ dissolution medium at $37^{\circ} \mathrm{C}$ and it was stirred at $100 \mathrm{rpm}$ for maintaining uniform drug concentration. $0.05 \mathrm{M}$ USP phosphate buffer solutions of $\mathrm{pH} 1 \cdot 2,5 \cdot 5$ and 7.5 were used as dissolution medium. Tramadol $\mathrm{HCl}$ release was measured at $\lambda_{\max } 271 \mathrm{~nm}$ using spectrophotometer (IRMECO, UV-Vis. U2020). Each time $5 \mathrm{ml}$ solution was taken for UV analysis and same amount of solution was replaced with fresh USP phosphate buffer solution (Serraa et al 2006; Siemoneit et al 2006).

\subsection{Kinetics of drug release}

Release of tramadol $\mathrm{HCl}$ was studied using various kinetic models like zero-order, first-order, Higuchi and Peppas models. For this purpose, release profiles were analysed using the following equations: Zero-order kinetics (Najib and Suleiman 1985)

$$
F_{\mathrm{t}}=K_{0} t,
$$

where $F$ represents the fraction of drug release in time, $t$ and $K_{0}$ is the zero-order release constant.

First-order kinetics (Desai et al 1966)

$$
\ln F_{\mathrm{t}}=\ln F_{0}+K_{1} t,
$$

where $F$ represents the fraction of drug release in time, $t$, and $K_{1}$ the first-order release constant.

Higuchi model (Higuchi 1963)

$$
F=K_{2} t^{1 / 2},
$$

where $F$ represents the fraction of drug release in time $t$ and $K_{2}$ the Higuchi constant. 
Peppas model (Peppas 1985)

$$
\frac{M_{\mathrm{t}}}{M_{\infty}}=K_{3} t^{n}
$$

where $M_{\mathrm{t}}$ is the weight of water absorbed at any time, $t$ and $M_{\infty}$ is the weight of water at equilibrium. $K_{3}$ is a constant describing the structural and geometric characteristics of the gels. $n$ is the release exponent when $n=0.45$ order of release is Fickian, $n=0.89$ corresponds to case II transport, while $0.45<n<0.89$ the diffusional mechanism is non-Fickian (Higuchi 1963; Korsmeyer et al 1983). No kinetic data or $n$ values were calculated when values of swelling coefficient and drug release were not significant.

\subsection{Sol-gel fraction analysis}

Sol-gel fraction analysis was used to determine the amount of un-crosslinked polymer present in the gels. For this purpose, hydrogels were cut into discs of 3-4 mm in size. These discs were dried first at room temperature and then in an vacuum oven at $45^{\circ} \mathrm{C}$ until constant weights were obtained. Then these discs were subjected to soxhelt extraction using deionized water at boiling temperature for $4 \mathrm{~h}$. Extraction results in the removal of un-crosslinked polymers or monomers from the gels. Extracted gels were dried again in vacuum oven at $45^{\circ} \mathrm{C}$ until constant weights were obtained. Gel fraction was determined using initial weight of dry gel and weight of extracted dry gel according to the following equations

$$
\text { Sol fraction }(\%)=\frac{W_{0}-W_{i}}{W_{0}} \times 100,
$$

$$
\text { Gel fraction }(\%)=100-\text { Sol fraction, }
$$

where $W_{0}$ is the dry weight of the hydrogel and $W_{i}$ the dried weight of the hydrogel after the extraction process (Liu et al 2007).

\subsection{Porosity measurement}

Solvent replacement method was used for porosity measurement. Weighed dried discs were immersed in absolute ethanol overnight and weighed after excess ethanol on the surface was blotted using blotting paper. Porosity was calculated using the following equation

$$
\operatorname{Porosity}(\%)=\left[\frac{M_{2}-M_{1}}{\rho V}\right] \times 100,
$$

where $M_{1}$ and $M_{2}$ are the weights of hydrogels before and after immersion in absolute ethanol, respectively. $\rho$ is the density of absolute ethanol and $V$ the volume of gel (Chang et al 2009).

\subsection{Diffusion coefficient}

Diffusion coefficient is the amount of solvent diffusing across the unit area through a concentration gradient in unit time (Crank 1975; Wu 2005). Diffusion coefficients from hydrogels were calculated using the following equation

$$
D=\pi\left(\frac{h \theta}{4 Q_{\mathrm{eq}}}\right)^{2},
$$

where $D$ is the diffusion coefficient of the hydrogels, $Q_{\text {eq }}$ the swelling of the gel at equilibrium, $\theta$ the slope of the linear part of the swelling curves and $h$ the initial sample thickness before swelling.

\subsection{Scanning electron microscopy (SEM)}

Morphology of hydrogel sample was investigated using scanning electron microscope S3400-N (Hitachi) (Liu et al 2007).

\subsection{Fourier transform infrared (FTIR) spectroscopy}

Dried discs of hydrogels were powdered in a pestle and mortar. Powder material and potassium bromide $(\mathrm{KBr})$ were mixed in $1: 100$ proportion and dried at $40^{\circ} \mathrm{C}$. Mixture was compressed to semitransparent disk of $12 \mathrm{~mm}$ diameter by applying a pressure of $65 \mathrm{kN}$ (pressure gauge, Shimadzu) for $2 \mathrm{~min}$. FTIR spectrum over the wavelength range $4000-400 \mathrm{~cm}^{-1}$ was recorded using FTIR Spectrometer (FT-IR 8400 S, Shimadzu).

\section{$2.13 X$-ray diffraction $(X R D)$}

X-ray diffraction patterns were recorded, in reflection, with a Bruker D8 Discover (Germany) instrument, at $25^{\circ} \mathrm{C}$ temperature, using nickel filtered $\mathrm{CuK} \alpha$ radiation ( $\lambda=1.54050 \AA)$ and operating at $35 \mathrm{kV}$ and $35 \mathrm{~mA}$. A system of diverging, receiving and anti-scattering slits of $1^{\circ}, 1^{\circ}, 1^{\circ}, 0 \cdot 15^{\circ}$, respectively was used.

\section{Results and discussion}

\subsection{Effect of AA on swelling and on drug release}

Swelling of hydrogel depends on polymer composition and nature of polymer used in hydrogel synthesis. Therefore, to study the effect of AA contents on swelling, a series of PCL/AA hydrogels were prepared containing varying amounts of AA i.e. $44 \mathrm{~g}, 52 \mathrm{~g}$ and $60 \mathrm{~g}$ per $100 \mathrm{~g}$ of solution at fixed PCL contents. EGDMA was added as cross-linker with different ratios with respect to the concentration of AA. Results of dynamic swelling behaviour are presented in figure 1 which shows an increase in swelling 
on increasing the concentration of AA. This increase in swelling was due to the presence of more carboxylic groups of AA available for ionization and this in turn causes electrostatic repulsion along the chain and results in the expansion of the originally coiled molecules. Equilibrium water content (EWC) of hydrogels at $\mathrm{pH} 6.5$ was also calculated and results are presented in table 3 . Ranjha and Mudassir (2008) prepared VAC-co-AA hydrogels and reported similar increase in swelling on increasing the amount of ionic monomer AA in the gels. Selected samples that showed higher swelling, were used for drug loading and release studies. Results of table 4 show the amount of tramadol $\mathrm{HCl}$ loaded by three different methods at various $\mathrm{pH}$ values. Drug release studies were carried out for a $12 \mathrm{~h}$ period. Results presented in figure 2 show that on increasing the concentration of AA

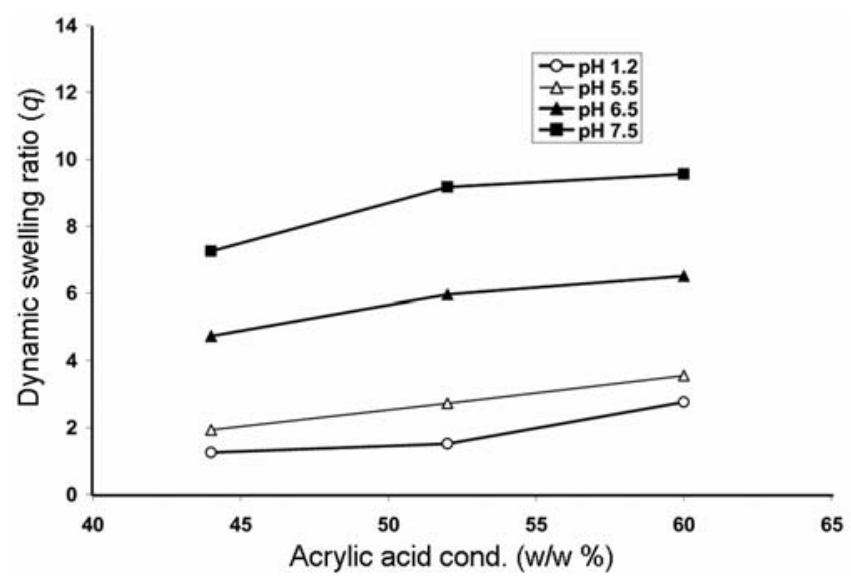

Figure 1. Dynamic swelling ratio of PCL/AA hydrogels with different concentrations of AA, i.e. $44 \mathrm{~g}, 52 \mathrm{~g}$ and $60 \mathrm{~g} / 100 \mathrm{~g}$ of solution using EGDMA as cross-linker, i.e. $1.0 \%$ of AA in various solutions of different $\mathrm{pH}$ at $37^{\circ} \mathrm{C}$. The $\mathrm{pH}$ values are: 1.2 $(\mathrm{O}), 5.5(\Delta), 6 \cdot 5(\mathbf{\Delta})$ and $7 \cdot 5(\mathbf{\Delta})$.

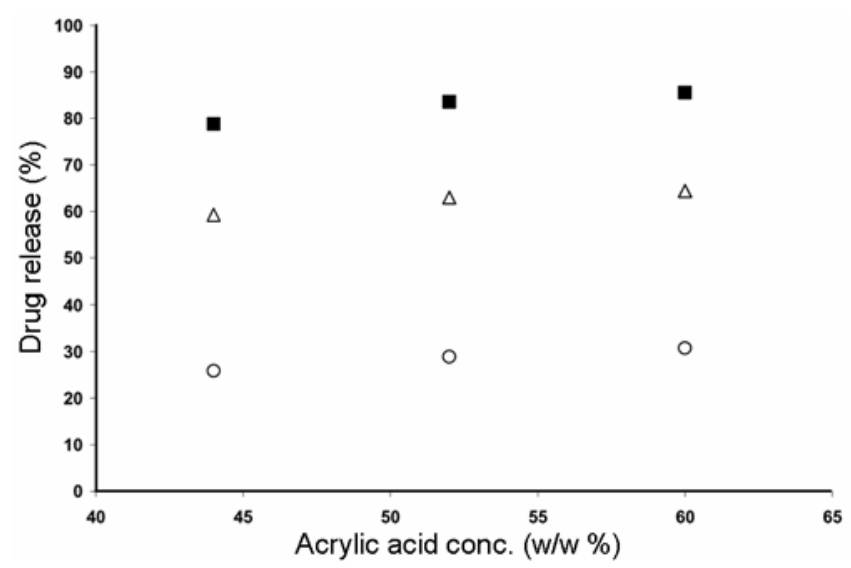

Figure 2. Release of tramadol $\mathrm{HCl}$ from PCL/AA hydrogels using different concentrations of AA, i.e. $44 \mathrm{~g}, 52 \mathrm{~g}$ and $60 \mathrm{~g} / 100 \mathrm{~g}$ of solution using EGDMA as cross-linker, i.e. $1 \cdot 0 \%$ of AA in various solutions of different $\mathrm{pH}$. The $\mathrm{pH}$ values are: $1 \cdot 2(0), 5 \cdot 5(\Delta)$ and $7.5(\mathbf{\square})$. from $44 \mathrm{~g}$ to $60 \mathrm{~g}$ per $100 \mathrm{~g}$ of solution, drug release increases from $25.88 \%$ to $30.74 \%$ at $\mathrm{pH} 1.2$, from $59.28 \%$ to $64.43 \%$ at $\mathrm{pH} 5.5$ and from $78.72 \%$ to $85.54 \%$ at $\mathrm{pH}$ $7 \cdot 5$. These findings are consistent with results reported by Ranjha and Mudassir (2008). They prepared VAC-co-AA hydrogels and loaded them with aspirin as model drug. They reported that aspirin release increases on increasing the AA contents in the gels (Ranjha and Mudassir 2008).

\subsection{Effect of PCL on swelling and on drug release}

In order to study the effect of PCL on swelling and on drug release, a second series of PCL/AA hydrogels was prepared using varying amounts of PCL i.e. $4 \mathrm{~g}, 8 \mathrm{~g}$ and $12 \mathrm{~g}$ per $100 \mathrm{~g}$ of solution at fixed AA contents. Figure 3 shows the effect of varying PCL concentration on swelling. Results show that swelling of gels decreases on increasing the concentration of PCL. Increase in PCL contents in the gels result in the reduction of the water diffusion ability and decrease relaxation of the polymer chains. PCL containing networks are semi-crystalline in nature and water could penetrate into the gels only due to amorphous region (Chiellini and Solaro 1996). The longer hydrocarbon chain in the PCL backbone makes it more hydrophobic (Wang et al 2009). Wang et al (2009) prepared poly(ethylene glycol) methyl ether-polycaprolactone (MPEG-PCL) hydrogels. They reported that swelling of hydrogels decreases due to increased hydrophobicity of PCL segment in the gels. However, swelling increases due to increase in hydrophilic segment i.e. presence of carboxyl group in PMAA in the gel. In another paper, David et al (2005) prepared hydogels containing HEMA and PCL. They reported that greater water retention ability was exhibited by $p$ (HEMA) whereas PCL showed minimal water retention ability. However, effect of varying the amount of PCL on drug release was not significant.

\subsection{Effect of EGDMA on swelling and on drug release}

Swelling and drug release from PCL/AA hydrogels can be modified by varying the amounts of EGDMA in the gels. For this purpose, third series of PCL/AA hydrogels was prepared using varying amounts of EGDMA, i.e. $0.25,0.75$ and $1.25 \% \mathrm{w} / \mathrm{w}$ of EGDMA with respect to the concentration of AA. Figures 4 and 5 show swelling and drug release behaviour, respectively, from the samples containing varying amount of EGDMA. It was observed that both swelling and drug release from the gels decrease on increasing EGDMA contents. It is concluded that EGDMA promotes the physical entanglements between hydrogels which provide elastic restrain forces and retard the expanding of the networks in the gels. However, this effect was not significant on varying $\mathrm{pH}$ of the swelling and drug release media. David et al (2005) 
Table 3. Diffusion coefficients and equilibrium swelling ratio of different formulations of PCL/AA hydrogel.

\begin{tabular}{|c|c|c|c|c|c|c|}
\hline \multirow[b]{2}{*}{ Sample code } & \multirow[b]{2}{*}{$D\left(10^{-6} \mathrm{~cm}^{2} / \mathrm{s}\right)$} & \multirow[b]{2}{*}{$\%$ EWC 6.5} & \multicolumn{4}{|c|}{$\begin{array}{l}\text { Equilibrium swelling coefficient in } \\
\text { solution of various } \mathrm{pH}\end{array}$} \\
\hline & & & $1 \cdot 2$ & $5 \cdot 5$ & $6 \cdot 5$ & $7 \cdot 5$ \\
\hline$S_{1}$ & $10 \cdot 31$ & $688 \cdot 12$ & 1.99 & $3 \cdot 55$ & $24 \cdot 04$ & $\mathrm{a}$ \\
\hline$S_{2}$ & $5 \cdot 85$ & $559 \cdot 75$ & $3 \cdot 75$ & $5 \cdot 83$ & $41 \cdot 70$ & $\mathrm{a}$ \\
\hline$S_{3}$ & $2 \cdot 42$ & $480 \cdot 93$ & $4 \cdot 36$ & $6 \cdot 08$ & $59 \cdot 12$ & $\mathrm{a}$ \\
\hline$S_{4}$ & $8 \cdot 96$ & $424 \cdot 23$ & $3 \cdot 16$ & $5 \cdot 81$ & $36 \cdot 18$ & $\mathrm{a}$ \\
\hline$S_{5}$ & $9 \cdot 11$ & $398 \cdot 67$ & $2 \cdot 90$ & $5 \cdot 45$ & $34 \cdot 11$ & $\mathrm{a}$ \\
\hline$S_{6}$ & na & na & $2 \cdot 27$ & $5 \cdot 02$ & $\mathrm{a}$ & $\mathrm{a}$ \\
\hline$S_{7}$ & $2 \cdot 25$ & $381 \cdot 55$ & $4 \cdot 43$ & $6 \cdot 73$ & 59.90 & $\mathrm{a}$ \\
\hline$S_{8}$ & $4 \cdot 47$ & $380 \cdot 94$ & $4 \cdot 07$ & $6 \cdot 01$ & 54.07 & $\mathrm{a}$ \\
\hline$S_{9}$ & $5 \cdot 78$ & $244 \cdot 74$ & $3 \cdot 23$ & $5 \cdot 75$ & 38.94 & $\mathrm{a}$ \\
\hline
\end{tabular}

$a$ stands for broken samples.

Table 4. Amount of tramadol $\mathrm{HCl}$ loaded by three different methods and its release from different formulations of PCL/AA hydrogel at various $\mathrm{pH}$ values.

\begin{tabular}{|c|c|c|c|c|c|c|}
\hline \multirow[b]{2}{*}{ Sample code } & \multicolumn{3}{|c|}{ Amount of tramadol $\mathrm{HCl}$ loaded (g/g of dry gel) } & \multicolumn{3}{|c|}{ Amount of tramadol $\mathrm{HCl}$ released (\%) } \\
\hline & By swelling & By extraction & By weight & $\mathrm{pH} 1 \cdot 2$ & $\mathrm{pH} 5 \cdot 5$ & $\mathrm{pH} 7 \cdot 5$ \\
\hline$S_{1}$ & $0 \cdot 0823$ & $0 \cdot 0801$ & $0 \cdot 0815$ & $25 \cdot 88$ & $59 \cdot 28$ & $78 \cdot 72$ \\
\hline$S_{2}$ & $0 \cdot 1298$ & $0 \cdot 1164$ & $0 \cdot 1245$ & $28 \cdot 91$ & $62 \cdot 98$ & $83 \cdot 56$ \\
\hline$S_{3}$ & $0 \cdot 1365$ & $0 \cdot 1201$ & $0 \cdot 1336$ & $30 \cdot 74$ & $64 \cdot 43$ & $85 \cdot 54$ \\
\hline$S_{7}$ & $0 \cdot 1583$ & $0 \cdot 1497$ & $0 \cdot 1548$ & $35 \cdot 65$ & $67 \cdot 42$ & 91.91 \\
\hline$S_{8}$ & $0 \cdot 1489$ & $0 \cdot 1412$ & $0 \cdot 1469$ & $33 \cdot 20$ & $65 \cdot 52$ & $86 \cdot 54$ \\
\hline$S_{9}$ & $0 \cdot 1218$ & $0 \cdot 1127$ & $0 \cdot 1201$ & $27 \cdot 41$ & $60 \cdot 29$ & $81 \cdot 32$ \\
\hline
\end{tabular}

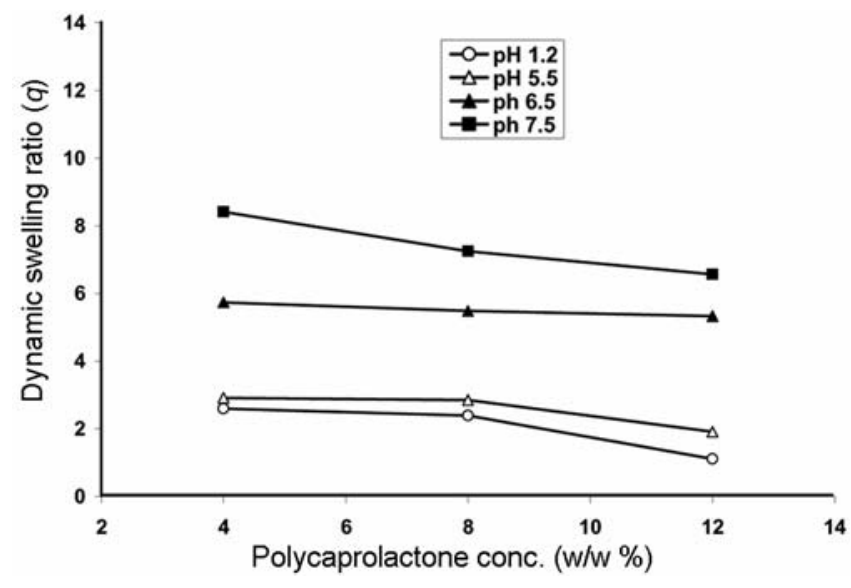

Figure 3. Dynamic swelling ratio of PCL/AA hydrogels with different concentrations of PCL, i.e. $4 \mathrm{~g}, 8 \mathrm{~g}$ and $12 \mathrm{~g} / 100 \mathrm{~g}$ of solution using EGDMA as cross-linker, i.e. $1.0 \%$ of AA in various solutions of different $\mathrm{pH}$ at $37^{\circ} \mathrm{C}$. The $\mathrm{pH}$ values are: $1 \cdot 2$ $(\mathrm{O}), 5 \cdot 5(\Delta), 6 \cdot 5(\mathbf{\Delta})$ and $7 \cdot 5(\mathbf{\square})$.

reported results consistent with present study. They prepared IPN containing 20\% w/w PCL, $p$ (HEMA) both in the presence and absence of EGDMA \% w/w by free radical polymerization using benzoyl peroxide as initiator.
They reported that water uptake was increased in the gels prepared without EGDMA as compared to the gels prepared using EGDMA. From drug release studies it was observed that on increasing EGDMA contents from 0.25$1.25 \% \mathrm{w} / \mathrm{w}$ with respect to the concentration of AA, drug release decreases from $35 \cdot 66-27.41 \%$ at $\mathrm{pH} 1.2$, from $67.42-60.29 \%$ at $\mathrm{pH} 5.5$ and from $91.91-81.33 \%$ at $\mathrm{pH}$ $7 \cdot 5$, respectively (Li et al 2006).

\subsection{Kinetics of drug release}

Various drug release models were used for studying the drug release kinetics. Criteria for selecting the most appropriate model were based on the ideal fit indicated by the values of regression coefficient $(r)$ near to 1 . Regression coefficient $(r)$ values obtained from PCL/AA hydrogels at varying contents of AA and EGDMA are given in table 5. Values of $r$ obtained using zero order release model were found higher than using first order release model, thus indicating that drug release from the samples at varying amount of AA and EGDMA was zero order.

Results presented in table 6 show the effects of AA and EGDMA contents on $n$ values, respectively. Values of 
Table 5. Effect of different concentrations of AA and EGDMA on drug release kinetics from PCL/AA hydrogel in various solutions of different $\mathrm{pH}$ using EGDMA as cross-linking agent i.e. $1 \%$ of AA.

\begin{tabular}{|c|c|c|c|c|c|c|c|c|}
\hline \multirow[b]{2}{*}{ Sample code } & & \multirow[b]{2}{*}{$\mathrm{pH}$} & \multicolumn{2}{|c|}{ Zero order kinetics } & \multicolumn{2}{|c|}{ First order kinetics } & \multicolumn{2}{|c|}{ Higuchi model } \\
\hline & & & $K_{0}\left(\mathrm{~h}^{-1}\right)$ & $r$ & $K_{1}\left(\mathrm{~h}^{-1}\right)$ & $r$ & $K_{2}\left(\mathrm{~h}^{-1}\right)$ & $r$ \\
\hline \multicolumn{9}{|l|}{ AA contents } \\
\hline \multirow[t]{3}{*}{$S_{1}$} & 44 & $1 \cdot 2$ & $0 \cdot 0252$ & 0.9946 & $0 \cdot 0216$ & 0.9903 & 0.0925 & 0.9943 \\
\hline & & $5 \cdot 5$ & $0 \cdot 0488$ & 0.9995 & $0 \cdot 0727$ & 0.9914 & $0 \cdot 2037$ & 0.9782 \\
\hline & & $7 \cdot 5$ & $0 \cdot 0587$ & 0.9963 & $0 \cdot 1171$ & 0.9889 & $0 \cdot 2495$ & 0.9920 \\
\hline \multirow[t]{3}{*}{$S_{2}$} & 52 & $1 \cdot 2$ & $0 \cdot 0285$ & 0.9919 & 0.0238 & 0.9862 & $0 \cdot 1026$ & 0.9955 \\
\hline & & $5 \cdot 5$ & $0 \cdot 0499$ & 0.9924 & 0.0759 & $0 \cdot 9689$ & $0 \cdot 2047$ & 0.9547 \\
\hline & & $7 \cdot 5$ & $0 \cdot 0614$ & 0.9981 & $0 \cdot 1324$ & 0.9719 & $0 \cdot 2584$ & 0.9839 \\
\hline \multirow[t]{3}{*}{$S_{3}$} & 60 & $1 \cdot 2$ & $0 \cdot 0240$ & 0.9736 & $0 \cdot 0202$ & 0.9633 & $0 \cdot 0891$ & 0.9940 \\
\hline & & $5 \cdot 5$ & $0 \cdot 0631$ & 0.9971 & $0 \cdot 0430$ & $0 \cdot 9879$ & $0 \cdot 1847$ & $0 \cdot 9949$ \\
\hline & & $7 \cdot 5$ & $0 \cdot 0541$ & $0 \cdot 9876$ & $0 \cdot 0978$ & $0 \cdot 9985$ & $0 \cdot 2324$ & 0.9936 \\
\hline \multicolumn{9}{|c|}{ EGDMA contents } \\
\hline \multirow[t]{3}{*}{$S_{7}$} & $0 \cdot 25 \%$ & $1 \cdot 2$ & 0.0359 & $0 \cdot 9883$ & $0 \cdot 0286$ & 0.9786 & $0 \cdot 1243$ & 0.9959 \\
\hline & & $5 \cdot 5$ & 0.0913 & 0.9976 & $0 \cdot 0537$ & 0.9955 & $0 \cdot 2276$ & 0.9895 \\
\hline & & $7 \cdot 5$ & $0 \cdot 2031$ & 0.9949 & $0 \cdot 0706$ & 0.9763 & $0 \cdot 3066$ & 0.9933 \\
\hline \multirow[t]{3}{*}{$S_{8}$} & $0 \cdot 75 \%$ & $1 \cdot 2$ & 0.0305 & $0 \cdot 9980$ & $0 \cdot 0254$ & 0.9949 & $0 \cdot 1082$ & 0.9914 \\
\hline & & $5 \cdot 5$ & 0.0299 & 0.9916 & $0 \cdot 0780$ & $0 \cdot 9870$ & $0 \cdot 2120$ & 0.9966 \\
\hline & & $7 \cdot 5$ & $0 \cdot 0667$ & 0.9986 & $0 \cdot 1471$ & 0.9759 & $0 \cdot 2807$ & 0.9857 \\
\hline \multirow[t]{3}{*}{$S_{9}$} & $1 \cdot 25 \%$ & $1 \cdot 2$ & $0 \cdot 0231$ & 0.9901 & 0.0272 & 0.9947 & 0.0989 & 0.9934 \\
\hline & & $5 \cdot 5$ & $0 \cdot 0455$ & 0.9971 & 0.0695 & $0 \cdot 9892$ & $0 \cdot 1918$ & $0 \cdot 9845$ \\
\hline & & $7 \cdot 5$ & $0 \cdot 0609$ & 0.9766 & $0 \cdot 1266$ & 0.9986 & $0 \cdot 2655$ & 0.9978 \\
\hline
\end{tabular}

Table 6. Effect of different concentrations of AA and EGDMA on drug release mechanism from PCL/AA hydrogel in various solutions of different $\mathrm{pH}$ using EGDMA as crosslinking agent i.e. $1 \%$ of AA.

\begin{tabular}{|c|c|c|c|c|c|}
\hline Samples code & AA contents & $\mathrm{pH}$ & $n$ & $r$ & Order of release \\
\hline \multicolumn{6}{|l|}{ AA contents } \\
\hline \multirow[t]{3}{*}{$S_{1}$} & 44 & $1 \cdot 2$ & $0 \cdot 8247$ & 0.9939 & Non-fickian \\
\hline & & $5 \cdot 5$ & $0 \cdot 7982$ & 0.9934 & Non-fickian \\
\hline & & $7 \cdot 5$ & $0 \cdot 6557$ & 0.9925 & Non-fickian \\
\hline \multirow{3}{*}{$S_{2}$} & 52 & $1 \cdot 2$ & 0.7814 & 0.9962 & Non-fickian \\
\hline & & $5 \cdot 5$ & 0.6385 & 0.9806 & Non-fickian \\
\hline & & $7 \cdot 5$ & $0 \cdot 6026$ & $0 \cdot 9870$ & Non-fickian \\
\hline \multirow[t]{3}{*}{$S_{3}$} & 60 & $1 \cdot 2$ & 0.7734 & 0.9797 & Non-fickian \\
\hline & & $5 \cdot 5$ & $0 \cdot 7454$ & 0.9972 & Non-fickian \\
\hline & & $7 \cdot 5$ & $0 \cdot 6423$ & $0 \cdot 9900$ & Non-fickian \\
\hline \multicolumn{6}{|c|}{ EGDMA contents } \\
\hline \multirow[t]{3}{*}{$S_{7}$} & $0 \cdot 25 \%$ & $1 \cdot 2$ & $0 \cdot 8272$ & 0.9926 & Non-fickian \\
\hline & & $5 \cdot 5$ & 0.7072 & 0.9875 & Non-fickian \\
\hline & & $7 \cdot 5$ & $0 \cdot 6333$ & $0 \cdot 9877$ & Non-fickian \\
\hline \multirow[t]{3}{*}{$S_{8}$} & $0.75 \%$ & $1 \cdot 2$ & $0 \cdot 8081$ & 0.9937 & Non-fickian \\
\hline & & $5 \cdot 5$ & 0.7576 & 0.9951 & Non-fickian \\
\hline & & $7 \cdot 5$ & $0 \cdot 7164$ & $0 \cdot 9853$ & Non-fickian \\
\hline \multirow[t]{3}{*}{$S_{9}$} & $1 \cdot 25 \%$ & $1 \cdot 2$ & $0 \cdot 7984$ & 0.9953 & Non-fickian \\
\hline & & $5 \cdot 5$ & $0 \cdot 7498$ & 0.9927 & Non-fickian \\
\hline & & $7 \cdot 5$ & $0 \cdot 6982$ & $0 \cdot 9962$ & Non-fickian \\
\hline
\end{tabular}

release exponent, $n$, using Peppas model for tramadol $\mathrm{HCl}$ loaded gels prepared using different contents of AA and EGDMA were found between 0.45 and 0.89 , thus indicating that drug release follows non-Fickian diffusion.

\subsection{Sol-gel analysis}

Sol-gel fraction analysis measures the un-crosslinked fraction of polymer or monomers in hydrogels. For this 
purpose sol-gel fraction analysis was performed on three series of hydrogels. Gel fraction of hydrogels was calculated using (10). Figure 6 shows the effect of varying amounts of PCL, AA and EGDMA on gel fraction. Results show that gel fraction is directly proportional to the concentration of PCL, AA and EGMDA.

\subsection{Porosity}

Figure 7 $(a-c)$ show the effect of varying amounts of PCL, EGDMA and AA on porosity of the gels. From results presented in figure 7(a) and (b), it was observed that porosity decreases on increasing the amount of PCL and EGDMA in the gels. Similar findings were reported by Chang et al (2006). They prepared PCL containing microporous matrices. They reported an increase in

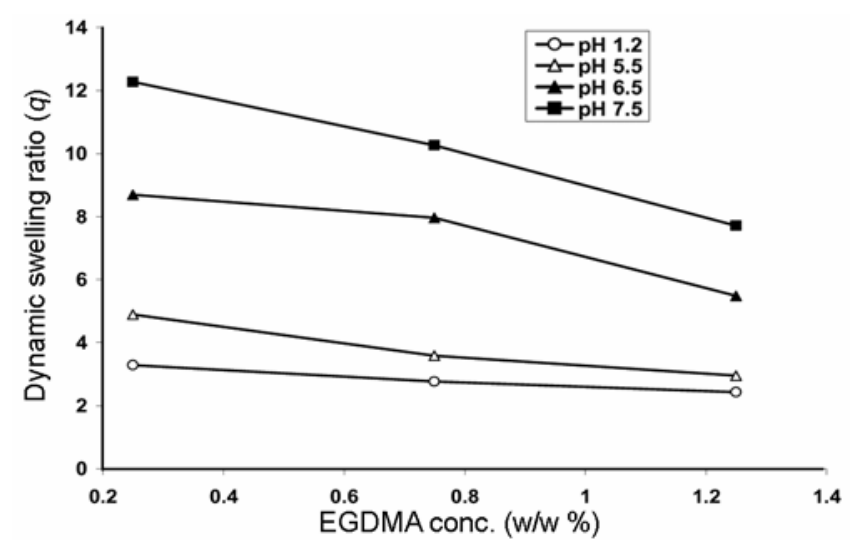

Figure 4. Dynamic swelling ratio of PCL/AA hydrogels using different concentrations of EGDMA as cross-linker, i.e. $0 \cdot 25 \%$, $0.75 \%$ and $1.25 \%$ of AA in various solutions of different $\mathrm{pH}$ at $37^{\circ} \mathrm{C}$. The $\mathrm{pH}$ values are: $1.2(\mathrm{O}), 5 \cdot 5(\Delta), 6 \cdot 5(\boldsymbol{\Delta})$ and $7.5(\boldsymbol{\square})$.

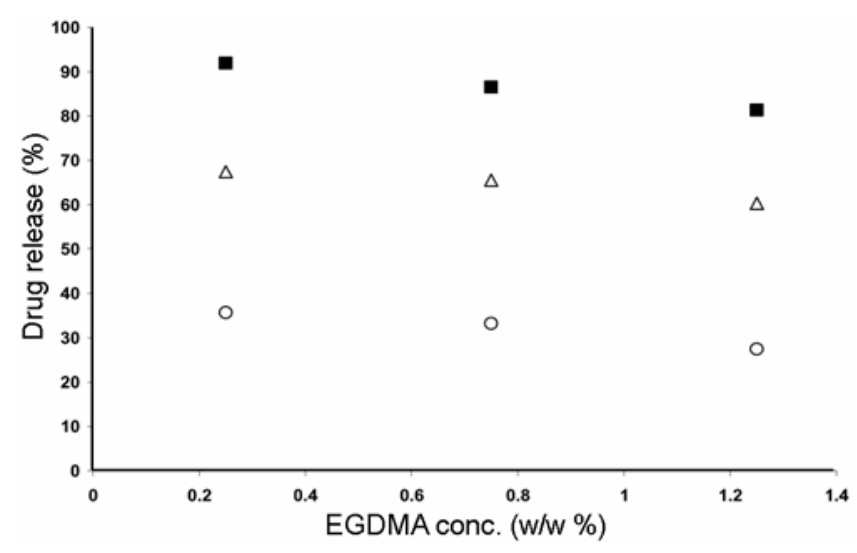

Figure 5. Release of tramadol $\mathrm{HCl}$ from PCL/AA hydrogels using different concentrations of EGDMA as cross-linker, i.e. $0.25 \%, 0.75 \%$ and $1.25 \%$ of AA in various solutions of different $\mathrm{pH}$ at $37^{\circ} \mathrm{C}$. The $\mathrm{pH}$ values are: $1.2(\mathrm{O}), 5.5(\Delta)$ and 7.5 (ם). porosity by almost $80 \%$ when formulated using $12.5 \%$ PCL solution. However, porosity was decreased on increasing PCL solution concentration. In another paper, Ranjha and Mudassir (2008) reported the decrease in porosity on increasing amount of EGDMA. It is suggested that EGDMA influence the crosslinked density and thus
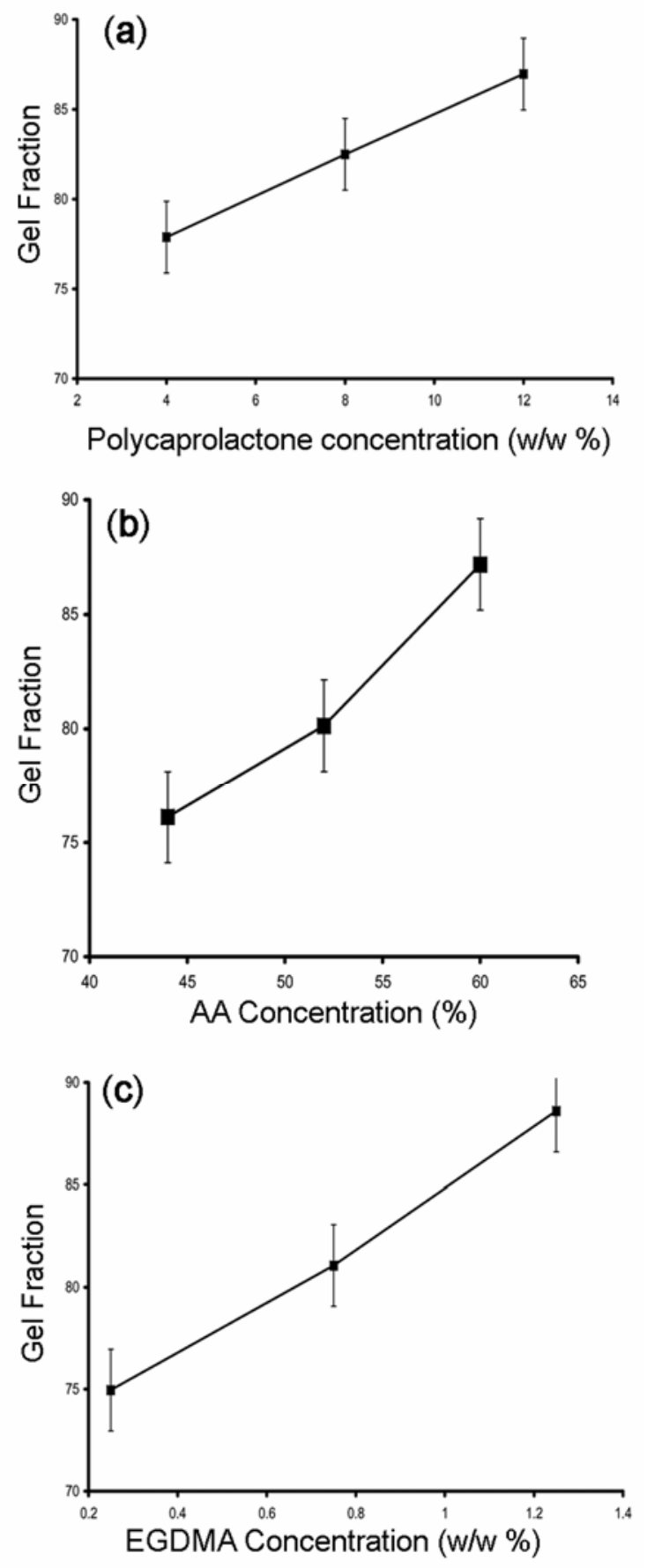

Figure 6. Gel fraction analysis (a) at different concentrations of PCL, i.e. $4 \mathrm{~g}, 8 \mathrm{~g}$ and $12 \mathrm{~g} / 100 \mathrm{~g}$ of solution; (b) at different concentrations of AA, i.e. $44 \mathrm{~g}, 52 \mathrm{~g}$ and $60 \mathrm{~g} / 100 \mathrm{~g}$ of solution and (c) different concentrations of EGDMA, i.e. $0 \cdot 25 \%, 0 \cdot 75 \%$ and $1.25 \%$ of AA. 

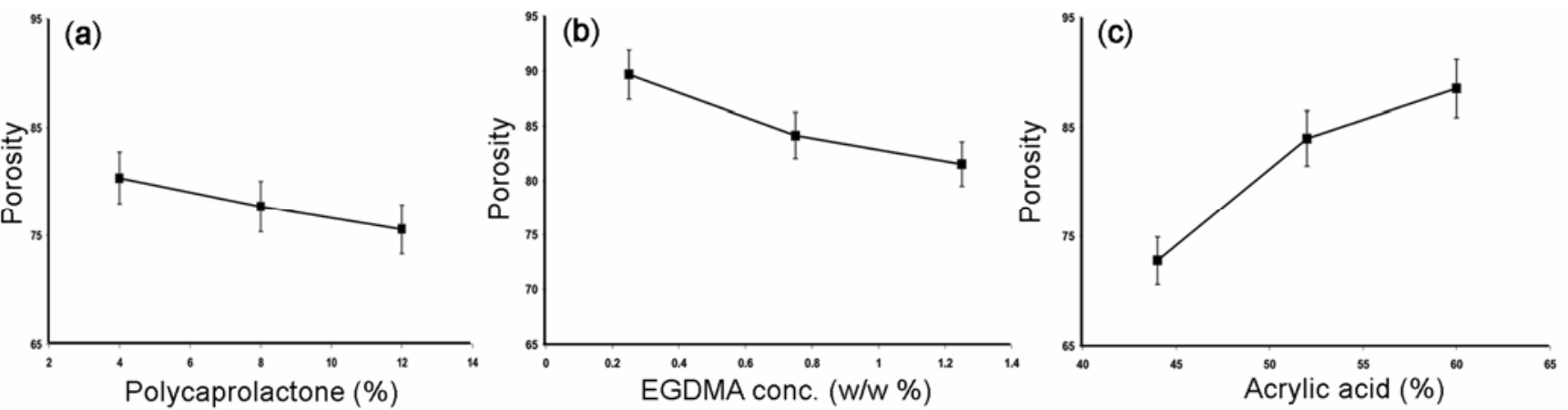

Figure 7. Porosity (a) at different concentrations of PCL, i.e. $4 \mathrm{~g}, 8 \mathrm{~g}$ and $12 \mathrm{~g} / 100 \mathrm{~g}$ of solution, (b) different concentrations of EGDMA, i.e. $0 \cdot 25 \%, 0 \cdot 75 \%$ and $1.25 \%$ of AA and (c) at different concentrations of AA, i.e. $44 \mathrm{~g}, 52 \mathrm{~g}$ and $60 \mathrm{~g} / 100 \mathrm{~g}$ of solution.
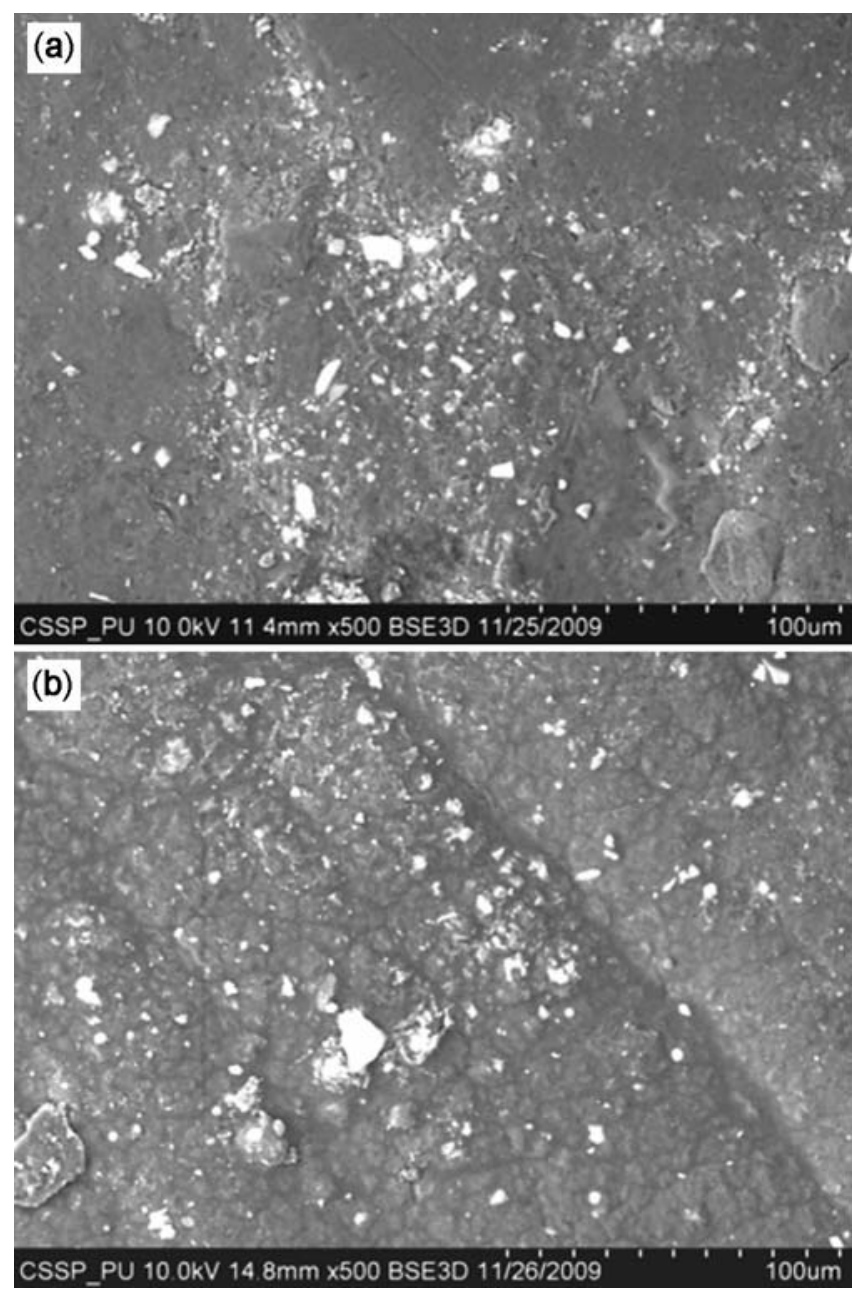

Figure 8. SEM of PCL/AA hydrogels: (a) unloaded hydrogel and (b) drug loaded hydrogel.

reduces the mesh size of prepared hydrogels. However, results presented in figure 7 (c) shows that on increasing the AA contents in the gels, porosity decreases.

\subsection{Diffusion coefficient}

Diffusion coefficient measures the diffusion of solute in hydrogels. Results of diffusion coefficient as calculated using (12) are given in table 3. Results indicate that diffusion coefficient increases on increasing the contents of AA in the gels. However, diffusion coefficient decreases on increasing PCL and EGDMA contents in the gels. This decrease in diffusion coefficient was due to decreased swelling (Crank 1975).

\subsection{Scanning electron microscopy}

Figure 8 shows SEM of unloaded and drug loaded hydrogels. SEM was employed for observing the surface morphology of drug loaded and unloaded PCL/ AA hydrogels. Examination of unloaded hydrogels show smooth and less porous surface. However, drug loaded hydrogels show rougher surface morphology. It seems that drug fills the pores and shows denser morpho$\log y$.

\subsection{Fourier transform infrared (FTIR) spectroscopy}

Figure $9(\mathrm{a}, \mathrm{b}$ and $\mathrm{d})$ show the peak at $1752 \mathrm{~cm}^{-1}$. This is due to stretching of the carboxylic acid, while the peaks at $3575 \mathrm{~cm}^{-1}$ show the stretching of $\mathrm{OH}$ group of carboxylic acid. In figure 9 (c) the medium peaks at 1030 $1070 \mathrm{~cm}^{-1}$, due to stretching vibration of $\mathrm{C}-\mathrm{O}-\mathrm{C}$ and $\mathrm{C}-$ $\mathrm{O}-\mathrm{H}$ bands of tramadol $\mathrm{HCl}$ are seen. A weak band at $1453 \mathrm{~cm}^{-1}$ is due to the $\mathrm{C}-\mathrm{N}$ stretching of bands of tramadol $\mathrm{HCl}$. Two peaks at $1560-1630 \mathrm{~cm}^{-1}$ are related to carboxylate $\mathrm{C}=\mathrm{O}$ stretching. The peaks at 1460 $1375 \mathrm{~cm}^{-1}$ are due to stretching of $\mathrm{CH}_{2}$ and $\mathrm{OH}$ group, respectively. FTIR analysis has proved that the hydrogels network was not a physical mixture and chemical linkages have formed during the free radical polymerization reaction. 


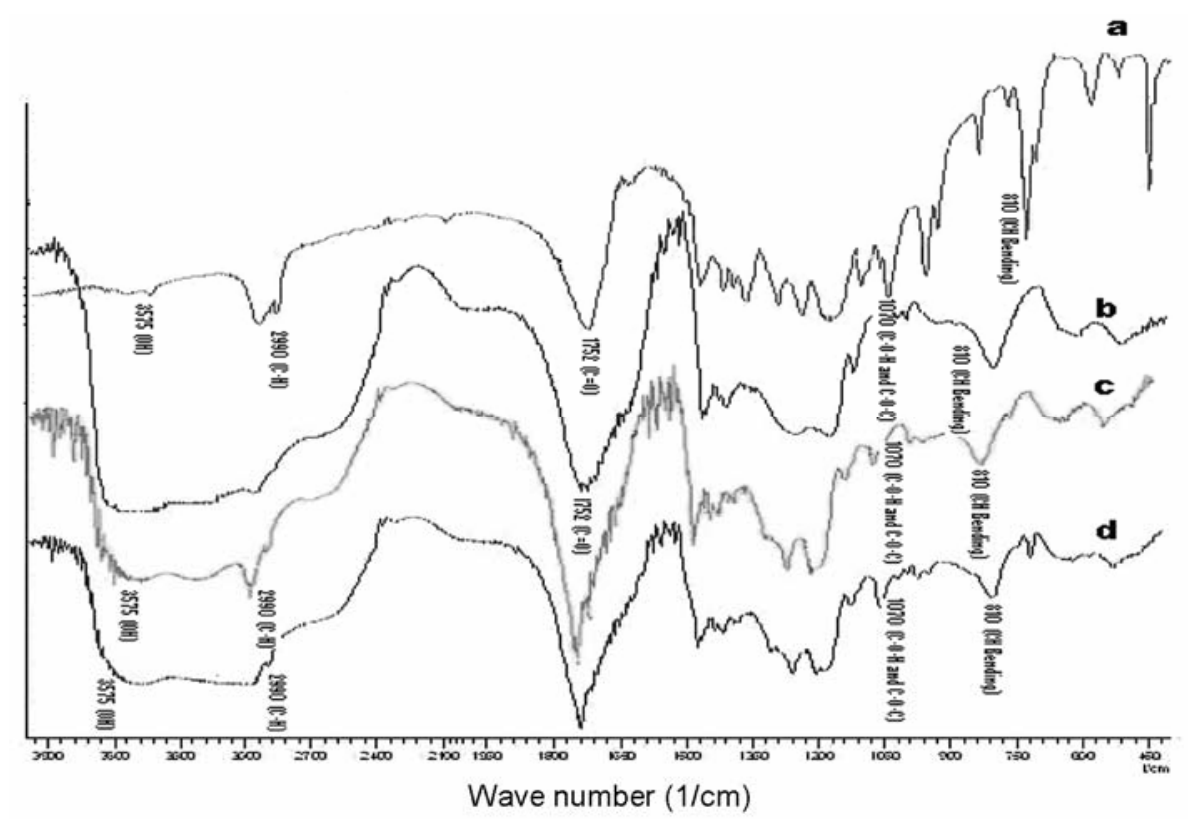

Figure 9. FTIR spectra of (a) PCL, (b) AA, (c) PCL/AA hydrogel without model drug and (d) PCL/AA hydrogel with model drug.

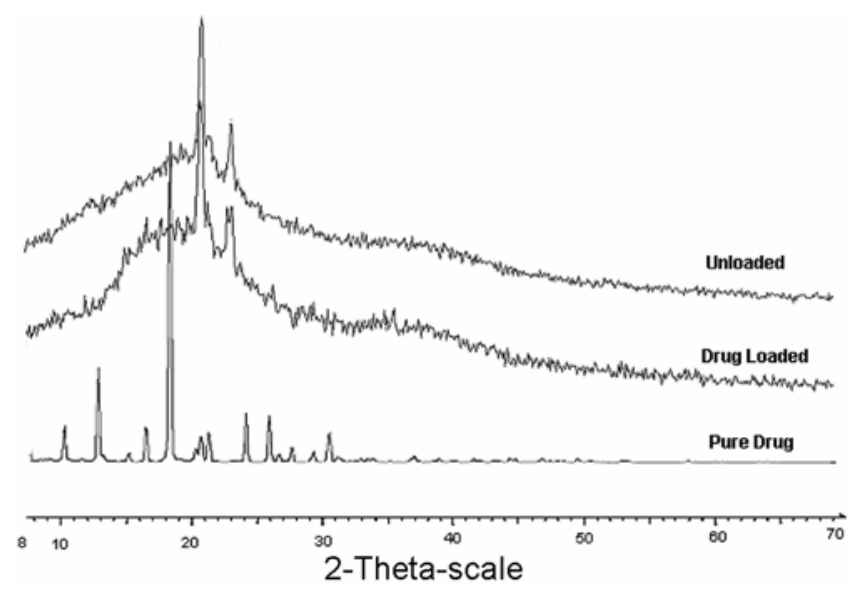

Figure 10. XRD spectra of unloaded hydrogel, drug loaded hydrogel and pure drug.

\section{$3.10 X$-ray diffraction $(X R D)$}

XRD spectrum of unloaded, drug loaded and pure drug are presented in figure 10. Eva software was used for data processing (Evaluation Package, Bruker, Germany). Patterns were obtained using a scan speed of 4 degree/min with $2 \theta$ between $5^{\circ}$ and $50^{\circ}$. X-ray diffraction spectra of PCL/AA hydrogel produced two peaks at about 23.8 and 21.38 which are caused by the blending of PCL with AA. Peaks show the formation of ester and amide carbonyl functional groups.

\section{Conclusions}

In the present work, $\mathrm{pH}$-sensitive, biodegradable PCL/ AA hydrogels have been developed by free radical polymerization using EGDMA as crosslinking agent and benzyl peroxide as initiator. It was observed that swelling of hydrogel increases on increasing the concentration of $\mathrm{AA}$ and decreases on increasing the concentration of PCL and EGDMA in the gels. Swelling was also increased at higher $\mathrm{pH}$ due to availability of more ionized carboxylic group of AA. Porosity and sol-gel analysis indicated that porosity and gel fraction increases on increasing the concentration of AA and PCL. It was observed that release of tramadol $\mathrm{HCl}$ decreases on increasing the amount of PCL and EGDMA, but tramadol $\mathrm{HCl}$ release increases on increasing the concentration of AA. FTIR, SEM and XRD were used to study the structure, morphology and crystallinity of hydrogels. The result confirms that PCL/AA hydrogel can be effectively used as $\mathrm{pH}$-sensitive controlled release drug delivery vehicle.

\section{References}

Arıca M Y, Altıntas B and Bayramoglu G 2009 Bioresource Technol. 100665

Bromberg L, Temchenko M, Alakhov V and Hatton A 2004 Int. J. Pharm. 28245

Chang H I, Perrie Y and Coombes AGA 2006 J. Controll. Rel. 110414

Chang K Y, Cheng L W, Ho G H, Huang Y P and Lee Y 2009 Acta Biomater. $\mathbf{5} 1937$

Chiellini E and Solaro R 1996 Adv. Mater. 8305

Crank J 1975 The mathematics of diffusion (Oxford: Oxford University Press) 2nd edn, pp 1-10

David S J, David W J, McLaughlin C P and McCoy S P 2005 Biomater. 261761

Desai S J, Singh P, Simonelli A P and Higuchi W I 1966 J. Pharm. Sci. 551230 
Devine D and Higginbotham C 2005 Eur. Polym. J. 41 1272

Higuchi T 1963 J. Pharm. Sci. 501145

Hong S W, Kim K H, Huh J, Ahn C H and Jo W H 2005 Macromol. Res. 13397

Jeong B, Bae Y H, Lee D S and Kim S W 1997 Nature 388860

Kim K H, Cui G H, Lim H J, June H, Cheol-Hee A and Jo W H 2004 Macromol. Chem. Phys. 2051684

Korsmeyer R W, Gurny R, Doelker E M, Buri P and Peppas N A 1983 Int. J. Pharm. 1525

Li X, Wu W, Wang J and Duan Y 2006 Carbohyd. Polym. 66 473

Liu C B et al 2007 Colloid Surf. A302 430

Masahiko O 2002 Prog. Polym. Sci. 2787

Mondrinos M J, Dembzynski R, Lu L, Byrapogu V K, Wootton

D M, Lelkes P I and Zhou J 2006 Biomater. 274399

Mudassir J and Ranjha N M 2008 J. Polym. Res. 15195

Najib N and Suleiman M 1985 Drug Dev. Ind. Pharm. 112169

Peppas N A 1985 Pharm. Acta Helv. 60110
Peppas N A and Khare A R 1993 Adv. Drug Del. Rev. 111

Peppas N A and Mikos A G 1986 in Preparation methods and structure (ed.) N A Peppas (Boca Raton, FL: CRC Press) Vol 1, pp 1-27

Peppas N A, Bures P, Leobandung W and Ichikawa H 2000 Eur. J. Pharm. Biopharm. 5027

Ranjha N M and Mudassir J 2008 Drug Develop. Ind. Pharm. 34512

Santiago L Y, Nowakc R W, Rubin J P and Marra K G 2006 Biomater. 272962

Seregin V V and Coffer J L 2006 Biomater. 274745

Serraa L, Nechc J D and Peppas N A 2006 Biomater. 27 5440

Siemoneit U, Schmitt C, Lorenzo C A, Luzardo A, Espinar F O, Concheiro A and Mendez J 2006 Int. J. Pharm. 31266

Wang K, Gou M L, Tu M J, Wei Y Q and Qian Z Y 2007 Colloid Surf. A302 430

Wang K et al 2009 Polym. Degrad. Stab. 94730

Wu C S 2005 Polymer 46147 